\title{
Complete androgen insensitivity syndrome associated with bilateral sertoli cell adenomas and unilateral paratesticular leiomyoma: A case report
}

\author{
Şenay Savaş-Erdeve ${ }^{1}$, Zehra Aycan ${ }^{1}$, Melikşah Keskin $^{1}$, Semra Çetinkaya ${ }^{1}$, Ayşe Karaman², \\ Sema Apaydın³, Emin Çakmakçı ${ }^{4}$ \\ Clinic of ${ }^{1}$ Pediatric Endocrinology, ${ }^{2}$ Pediatric Surgery, ${ }^{3}$ Pathology and ${ }^{4}$ Radiology, Dr. Sami Ulus Obstetrics and Gynecology \\ and Pediatrics Training and Research Hospital, Ankara, Turkey. E-mail: meliksah.keskin@hotmail.com \\ Received: 10th October 2015, Revised: 25th May 2016, Accepted: 31st October 2016
}

SUMMARY: Savaş-Erdeve Ş, Aycan Z, Keskin M, Çetinkaya S, Karaman A, Apaydın S, Çakmakçı E. Complete androgen insensitivity syndrome associated with bilateral sertoli cell adenomas and unilateral paratesticular leiomyoma: A case report. Turk J Pediatr 2016; 58: 654-657.

Complete androgen insensitivity syndrome (CAIS) disorder of sex development due to mutations that cause function loss in androgen receptors in 46, XY individuals. The risk of malignancy in CAIS is 5-10\% until the age of 25 years.

A 17-year-old patient raised as a female presented to our clinic complaining of amenorrhea. She had a history of surgery for inguinal hernia at the age of 2 years. The patient's niece of the same age had been diagnosed with CAIS at our department and gonadectomy had been performed six months ago. She had four other nieces with the same diagnosis. Her external genital appeared phenotypically female. On physical examination, breast development was Tanner stage 5 and pubic hair Tanner stage 2 with scarce axillary hair. The gonad was palpated in the left inguinal region. Chromosome analysis revealed 46, XY and sex determining region $\mathrm{Y}$ (SRY) was positive. The patient was diagnosed as CAIS with laboratory and radiology results. The Sexual Orientation and Gender Identity Committee decided on gonadectomy. Histopathological evaluation of the gonad revealed bilateral Sertoli cell tumor and right paratesticular leiomyoma.

Key words: complete androgen insensitivity syndrome, sertoli cell adenoma, sex differentiation.

Complete androgen insensitivity syndrome (CAIS) is a disorder of sex development with an incidence of 1 in 20,000-99,000 in genetic males. It is caused by loss of function mutations of the androgen receptor gene in individuals with an XY genotype. The gene encoding the androgen receptor is located on Xq containing 8 exons. A number of mutations have been identified in these 8 exons. ${ }^{1,2}$ Individuals with CAIS are phenotypically female with normal female external genitalia. The most common symptom is primary amenorrhea, although the diagnosis may be made earlier when there is a discrepancy between antenatal and postnatal phenotype or when an inguinal hernia in a young girl is found to contain a testis. Traditional management of CAIS includes gonadectomy with subsequent hormonal replacement. Gonadectomy is indicated owing to the increased incidence of gonadal tumors in CAIS, which range from $0.8 \%$ to $16 \%$. Current practice is to perform gonadectomy in late adolescence after completion of spontaneous pubertal development ${ }^{1}$.

Although the risk of gonadal tumor development is considered to be low, a variety of tumors have been described in association with CAIS. The case we present, a unilateral paratesticular leiomyoma developing concurrently with bilateral Sertoli cell adenomas, is very rarely reported in the literature.

\section{Case Report}

A 17-year-old patient, who had been raised as 
female, presented to our clinic for amenorrhea. Her history involved surgery for left inguinal hernia at the age of 2 . The patient's niece of the same age was diagnosed with CAIS at our department and had undergone gonadectomy six months ago. The patient had four more nieces with the same diagnosis. The phenotypically female patient's physical examination revealed: height $164.7 \mathrm{~cm}(-1.53 \mathrm{SDS})$, weight $54.5 \mathrm{~kg}$ (-2 SDS), breast development Tanner stage 5, and pubic hair development Tanner stage 2 with scarce axillary hair development. A gonad was palpable in the left inguinal region. Chromosome analysis was 46, XY, and the sex-determining region Y (SRY) was positive. Her laboratory analysis revealed $\mathrm{LH} 18.6 \mathrm{mIU} / \mathrm{ml}$ (1.7-11), FSH $0.7 \mathrm{mIU} / \mathrm{ml}$ (1.4-11.7), total testosterone $702 \mathrm{ng} / \mathrm{dl}$ (8-80), E2 $31.3 \mathrm{pg} / \mathrm{ml}$ (23-188), Anti-Mullerian hormone $8.2 \mathrm{ng} / \mathrm{ml}$ (0.8-14.2), dihydrotestosterone $18.2 \mathrm{ng} / \mathrm{dl}$ (5-22), 1-4 delta

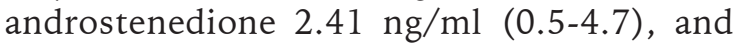
sex hormone binding globulin (SHBG) 59.7 nmol/L (18-145). Serum tumor marker results were lactate dehydrogenase (LDH) $146 \mathrm{IU} / \mathrm{L}$ (98-192), alpha-fetoprotein (AFP) $0.5 \mathrm{IU} / \mathrm{ml}$ (0.5-3.5) and $\beta-\mathrm{HCG}<2 \mathrm{mIU} / \mathrm{ml}(0.5-5.3)$. Suprapubic ultrasonography showed the right testis $29 \times 19 \times 22 \mathrm{~mm}$ in size in the right adnexa together with an adjacent cystic lesion $32 \times 25 \times 23 \mathrm{~mm}$ in size. In the left inguinal area, the left testis was $17 \times 9 \times 11 \mathrm{~mm}$ in size with an adjacent cystic lesion $38 \times 20 \times$ $18 \mathrm{~mm}$ in size. Mullerian structures could not be visualized. The pelvic magnetic resonance imaging of the patient revealed the right testis $36 \times 26 \times 25 \mathrm{~mm}$ in size in the right adnexal region with a cystic lesion $34 \times 18 \times 24 \mathrm{~mm}$ in size located at its anterior upper aspect. The left testis located in the left inguinal region was $35 \times 21 \times 12 \mathrm{~mm}$ in size and there was a paratesticular cyst $30 \times 15 \times 10 \mathrm{~mm}$ at its anterolateral aspect. The vagina was present but the uterus was not observed. Figures 1 and 2 present the patient's MR images. The findings on physical examination, laboratory tests and imaging investigations suggested CAIS and the patient was assessed by the Sexual Orientation and Gender Identity Committee. It was decided to perform gonadectomy due to increased risk of malignancy. Intraoperative images of the gonads are presented in Figures 3 and 4. Histopathological analysis of the biopsy materials taken from the gonads resulted in a diagnosis of well-differentiated Sertoli cell tumor and right-sided unilateral leiomyoma. Mullerian (tuba uterina) and Wolfian cystic structures were also observed. Figure 5 shows the histopathological images from the biopsy material.

\section{Discussion}

Complete androgen insensitivity syndrome (CAIS) is a sexual development disorder due to mutations that cause function loss in androgen receptors in $46, \mathrm{XY}$ individuals. It is characterized by a male karyotype and abnormal female phenotype with the absence of Mullerian duct derivatives and the presence of female breast development, although no

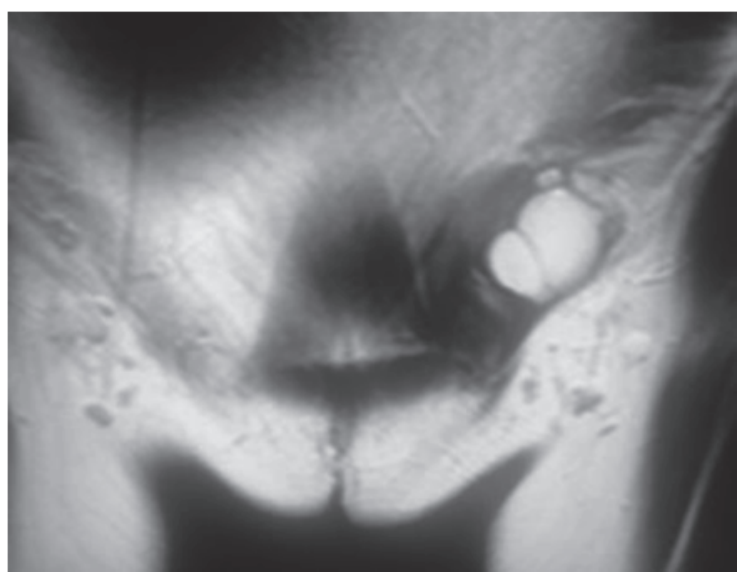

Fig. 1. Left testicle parenchyma with atrophic appearance on T2-weighed MRI on the coronal plane with paratesticular cyst formation with a fine septum adjacent to the anterolateral area

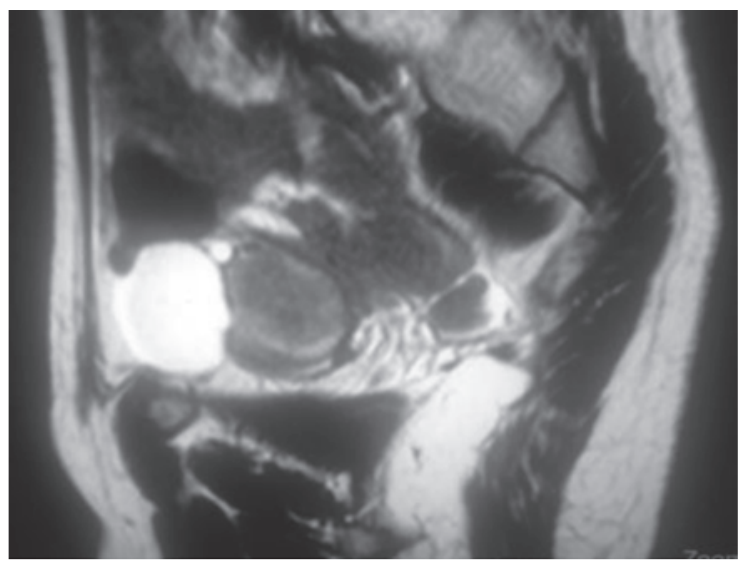

Fig. 2. T2-weighed MRI on the sagittal plane shows the right testis parenchyma to have smooth margins while the paratesticular cyst has a simple internal structure with lobule contours 


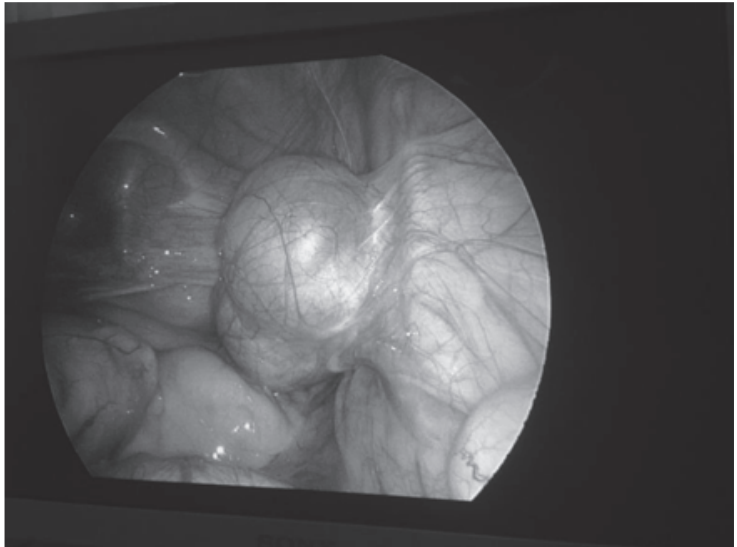

Fig. 3. Laparoscopic image of the right intraabdominal gonad

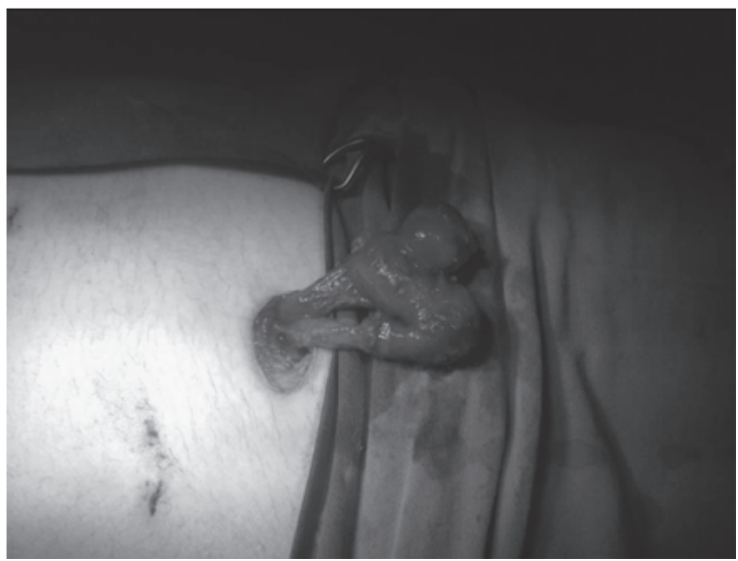

Fig. 4. Intraoperative image of the left inguinal gonad

axillary or pubic hair is observed ${ }^{2}$. Hormonal measurements classically reveal a plasma testosterone concentration that is within the normal range for males. However, some patients have elevated plasma testosterone as in our patient, due to increased response to stimulation by luteinizing hormone (LH). On the other hand, plasma follicle-stimulating hormone (FSH) concentrations might be within the normal range, and normal or elevated plasma LH concentrations may result from hypothalamo-pituitary refractoriness to the negative feedback of testosterone ${ }^{2}$.

The complete androgen insensitivity syndrome may be familial or sporadic ${ }^{3}$. Our patient's niece had been diagnosed with CAIS at our clinic and gonadectomy had been performed six months before. The patient also had four other nieces with the same diagnosis. The diagnosis is usually suspected at puberty because of amenorrhea, but can sometimes be made at an early age upon the discovery of an inguinal

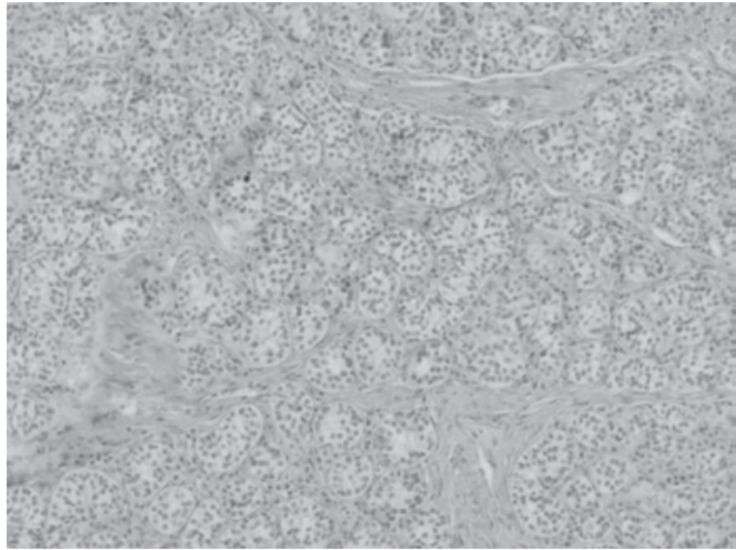

Fig. 5. Mature-looking Sertoli cells forming a tubular structure and Leydig cells are seen in the thin narrow fibrotic stroma in the tumoral tissue

hernia or after the condition is revealed in an affected sibling. It may also occasionally be discovered after marriage, even at an advanced age, as reported in an 84-year-old patient when an abdominal tumor became apparent ${ }^{3}$. About $50 \%$ of the patients have an inguinal hernia. Conversely, $1-2 \%$ of apparently female infants with inguinal hernia are diagnosed as having a 46, XY karyotype and CAIS 4 . Our patient was assessed for inguinal hernia when she was 2 years old but unfortunately had not been diagnosed at that time.

The standard practice is to recommend gonadectomy to all patients with CAIS after the completion of puberty, usually at the age of 16 years $^{1}$. The estimated risk of malignant development in the testes is $5 \%-10 \%$ until 25 years of age and increases thereafter to reach $33 \%$ at the age of $50^{2}$. In a case series of 43 patients with androgen insensitivity syndrome by Rutgers and Scully, hamartomas made up $63 \%$, sertoli cell adenomas $23 \%$ and malignant tumors including two seminomas, one intratubular germ cell neoplasm with early stromal invasion and a malignant sex cord tumor $9 \%^{5}$. Sertoli-Leydig cell tumors are uncommon neoplasms, accounting for only $1 \%$ of all sex-cord stromal tumors ${ }^{2}$. It is possible that gonadotropins induce gonocyte proliferation in the development of testicular cancer, and there is a positive correlation between elevated gonadotropins and the number of premeiotic germ cells. Some authors have tried to explain the relationship between this syndrome and neoplasia development, 
and have proposed a hypothesis of increased susceptibility due to the absence of germ cell differentiation, with gonocytes developing in a neoplastic manner6.

Leiomyomas are generally very unusual tumors in the urogenital tract, and especially in the testis or epididymis. Leiomyomas are also extremely rare in removed gonads from androgen insensitivity syndrome patients, with only three similar cases reported in the literature ${ }^{7-9}$. Their location may be intratesticular or paratesticular, and the origin is believed to be the smooth muscle cells of the interstitial stroma, the muscular layer of the vessels of the tunica albuginea, the seminiferous tubules, as well as paratesticular structures (spermatic cord, epididymis, vestigial remnants, and tunica vaginalis), although tubular genital structures are aplastic in CAIS patients due to the lack of androgen response ${ }^{7}$. The case we presented is very rarely reported in the literature with a right paratesticular leiomyoma developing concurrently with bilateral Sertoli cell adenomas.

\section{REFERENCES}

1. Nakhal RS, Hall-Craggs M, Freeman A, et al. Evaluation of retained testes in adolescent girls and women with complete androgen insensitivity syndrome. Radiology 2013; 268: 153-160.

2. Fagouri H, Moussaoui DR, Kouach J, et al. Complete androgen insensitivity syndrome with a Sertoli-Leydig cell tumor. J Pediatr Adolesc Gynecol 2014; 27: e113-e115.

3. Bisceglia M, Magro G, Ben Dor D. Familial complete androgen insensitivity syndrome (Morris syndrome or testicular feminization syndrome) in 2 sisters. Adv Anat Pathol 2008; 15: 113-117.

4. Asl Zare M, Kalantari MR, Asadpour AA, Kamalati A. Bilateral laparoscopic gonadectomy in a patient with complete androgen insensitivity syndrome and bilateralsertoli-leydig cell tumor: a case report and brief review of the literature. Nephrourol Mon 2014; 6: e15278.

5. Rutgers JL, Scully RE. The androgen insensitivity syndrome (testicular feminization): a clinicopathologic study of 43 cases. Int J Gynecol Pathol 1991; 10: 126144.

6. Aguilar-Ponce J, Chilaca Rosas F, Molina Calzada C, Granados García M, Jiménez Ríos MA, De la Garza Salazar J. Testicular cancer in androgen insensitivity syndrome in a Mexican population. Clin Transl Oncol 2008; 10: 840-843.
7. Siminas, S. Kokai, G, Kenny, SE. Complete androgen insensitivity syndrome associated with bilateral sertoli cell adenomas and paratesticular leiomyomas: case report and review of the literature. J Pediatr Urol 2013; 9: e31-e34.

8. Krichen Makni K, Mnif Hachicha SL, Ellouze S. Feminizing testicular syndrome with multiple hamartomas and bilateral paratesticular leiomyomas. Rev Med Interne 2005; 26: 980-983.

9. Goulis DG, Iliadou PK, Papanicolaou A, et al. R831X mutation of the androgen receptor gene in an adolescent with complete androgen insensitivity syndrome and bilateral testicular hamartomata. Hormones (Athens) 2006; 5: 200-204. 